\title{
Erratum to: Use of allochthonous resources by zooplankton in reservoirs
}

\author{
Kyle A. Emery • Grace M. Wilkinson • \\ Flannery G. Ballard · Michael L. Pace
}

Published online: 18 June 2015

(C) Springer International Publishing Switzerland 2015

\section{Erratum to: Hydrobiologia \\ DOI 10.1007/s10750-015-2338-6}

Due to an error in model transcription, the dietary water fraction was only applied to the zooplankton and Chaoborus algal fraction in the mixing model. The dietary water correction should have also been applied to the terrestrial fraction. The updated zooplankton and Chaoborus allochthony values are reported below along with corrected versions of Figs. 2 and 4. In the corrected model, the values for zooplankton and Chaoborus allochthony decreased approximately $15 \%$ but the patterns among reservoirs, the regression analysis, and the conclusion remain unchanged.

Crustaceous zooplankton allochthony varied among systems from 11 to 79\%, and Chaoborus allochthony, measured in four reservoirs, was similarly variable (22-80\%). The allochthonous fraction of zooplankton was variable but usually $<50 \%$ in all but two reservoirs. For most reservoirs the four pools of organic matter considered in this study (POM, DOM, zooplankton, Chaoborus) were over $20 \%$ allochthonous based on median values, but some zooplankton distributions had high uncertainty. 

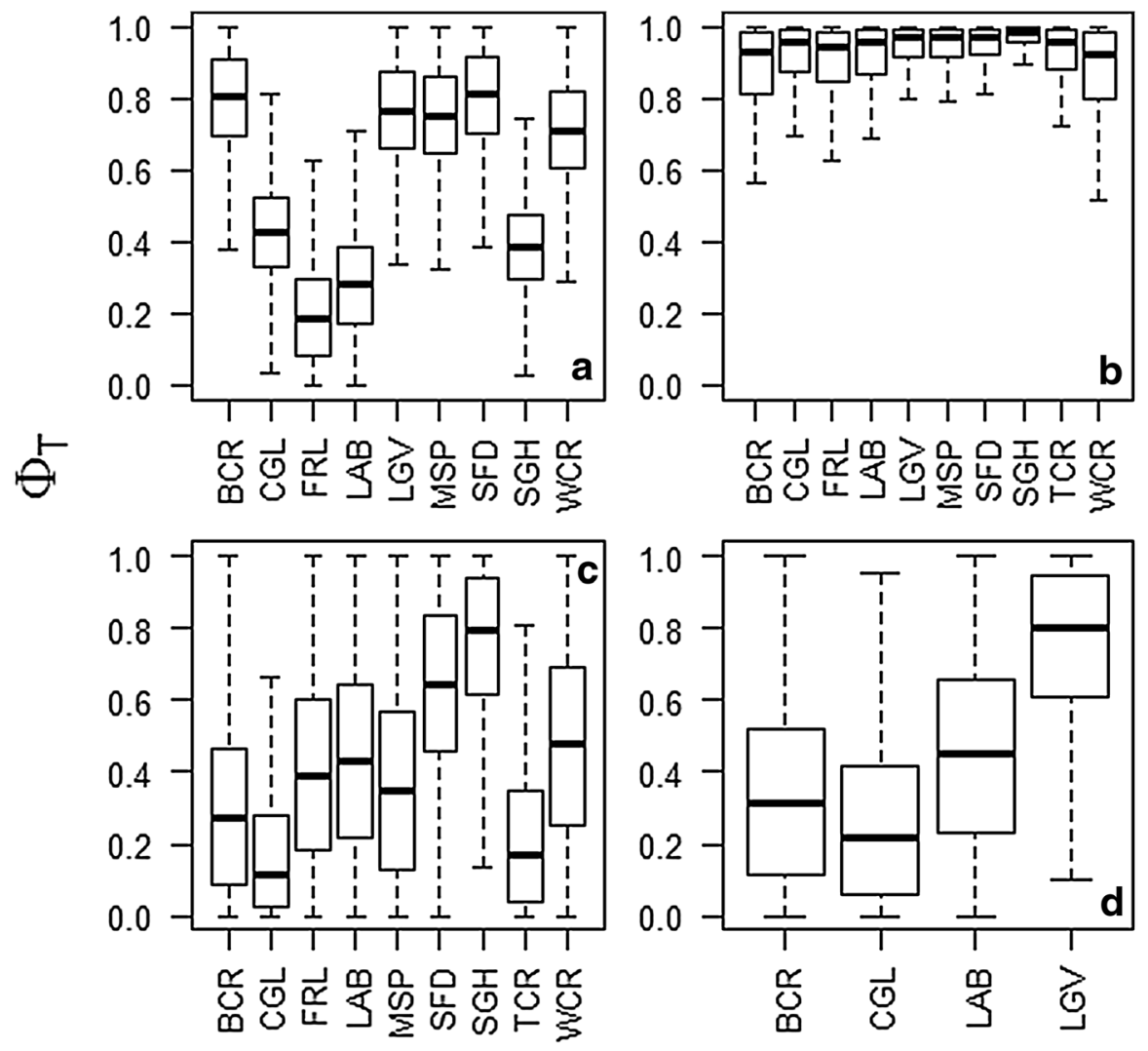

\section{Reservoir}

Fig. 2 Box plots of posterior distributions of modeled $\phi_{\mathrm{T}}$ for a POM, b DOM, c bulk zooplankton, and d Chaoborus. Reservoir codes are given in Table 1 


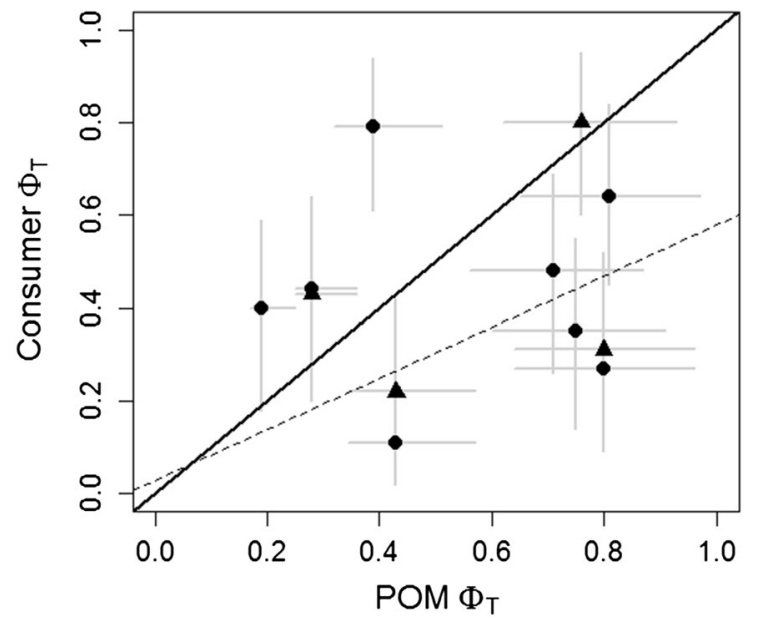

Fig. 4 The allochthonous fraction of resource pool (POM $\left.\phi_{\mathrm{T}}\right)$ versus the allochthonous fraction of the consumers (Zooplankton $\phi_{\mathrm{T}}$ and Chaoborus $\phi_{\mathrm{T}}$; circles and triangles, respectively). The gray lines extend from the $25 \%$ to the $75 \%$ quartiles of the posterior distributions. The solid line is the $1: 1$ line and the dotted line is the relationship between POM $\phi_{\mathrm{T}}$ and Chaoborus $\phi_{\mathrm{T}}$ from Wilkinson et al. (2013a) for comparison to the pattern often observed in lake ecosystems 